Research Article

\title{
Experimental and Numerical Investigation of Failure Characteristics and Mechanism of Granites with Different Joint Angles
}

\author{
Zhenhua Wang $\mathbb{D}^{1,2}$ Jun Fang, ${ }^{1}$ Gang Wang $\mathbb{D}^{3},{ }^{3}$ Yifan Jiang, ${ }^{4}$ and Dongwei Li $\mathbb{D}^{2}$ \\ ${ }^{1}$ School of Civil Engineering and Architecture, Wuhan University of Technology, Wuhan 430070, China \\ ${ }^{2}$ School of Civil and Architecture Engineering, East China University of Technology, Nanchang 330013, China \\ ${ }^{3}$ School of Civil Engineering, Shaoxing University, Shaoxing 312000, China \\ ${ }^{4}$ School of Civil Engineering, University of South China, Hengyang 421000, China
}

Correspondence should be addressed to Zhenhua Wang; zhh200802@163.com

Received 24 September 2021; Accepted 23 October 2021; Published 18 November 2021

Academic Editor: Xiao Wang

Copyright (c) 2021 Zhenhua Wang et al. This is an open access article distributed under the Creative Commons Attribution License, which permits unrestricted use, distribution, and reproduction in any medium, provided the original work is properly cited.

\begin{abstract}
The uniaxial compression tests were conducted on granite samples with different joint dip angles to more favorably explore the influences of the nonconsecutive joint on mechanical properties and deformation characteristics of the rock mass. The stress-strain curves, deformation and strength characteristics, and energy evolution process of the samples were analyzed. Numerical simulation using particle flow code (PFC) is employed to study the crack propagation process. The mode of jointed and fractured rock was investigated. The research results showed a significant reduction in both the peak strength and elastic modulus of jointed samples compared with intact ones: the peak strength and elastic modulus drop to the minimum at the joint dip angle of about $45^{\circ}$, especially for the peak strength, which takes up about $55 \%$ of the intact samples. The fractured samples' total energy, elastic strain energy, and dissipated energy during the uniaxial compression drop significantly relative to intact samples. The proportion of the fracture modes varies with different joint dip angles, in which the ratio of shear cracks grows at first and then declines, with the highest balance at the dip angle of $45^{\circ}$. The damage stress's sensitivity to the dip angle change is greater than that of the peak stress, with reduction amplitude more extensive than the latter.
\end{abstract}

\section{Introduction}

Various structural planes such as fractures, interlayers, and faults generally occur in engineering rock, so such rock has quite complex structures. Numerous engineering practices show that the instability of rock structures (e.g., rock slopes and underground caverns) is related to joints developed in rock $[1,2]$. The presence of fractures greatly influences various characteristics (such as deformation and strength) of rock [3-5]. Therefore, the investigation on the initiation, propagation, and coalescence processes of cracks in jointed rock shows great significance $[6,7]$.

Rock fracture is accompanied by the initiation, propagation, and coalescence of microfractures in rock. The macroscopic mechanical properties of the rock are highly associated with the development and evolution of microfractures [5, 8-11]. Thus, initial microfractures present a vital influence on the physical and mechanical properties of rock. At present, the related research mainly focuses on two aspects. On the one hand, simulation tests or numerical simulations are carried out to explore the influences of the occurrence, length, and opening of fractures on mechanical properties. For example, Gehle and Kutter [12] surveyed the effects of geometric parameters of discontinuous joints and loading conditions on the shear strength of rock. Fan et al. [12-14] explored the dip angle and length of microfractures and loading direction influences on the rock's crack initiation strength and deformation characteristics. Zhao et al. [15] investigated the shear behaviors of rock containing four joints with different occurrences based on numerical simulation. On the other hand, the relationship between the density of microfractures and the mechanical properties of specific rock is surveyed. For example, Moore and Lockner [16] 
explored the influence of the thickness of microfractures in granite on the shear strength of the rock. Kou and Alm [17] performed a Brazilian disc test on granite samples thermally treated at different temperatures. In addition, they also established the relationship between the tensile strength and the density of microfractures by analyzing microscopic and macroscopic mechanical properties of fractures. Feng [18] explored the influence of fractures in a variety of rock, including syenite, basalt, and gabbro, on the uniaxial compressive strength and tensile strength of the rock. By studying the relationship between microfractures and mechanical properties of marble in Yuen Long District, Hong Kong, China, Wang et al. [19] found that the density of microfractures is remarkably correlated with the compressive strength of brittle marble while hardly related to that of ductile marble. Wong et al. [20] explored the influences of the initial density of microfractures and mineral particle size on the uniaxial compressive strength of Yuen Long marble. Through numerical analysis, $\mathrm{Pu}$ et al. [21] revealed the effects of fractures' distribution density and dip angle on the failure strength of rock-like materials. $\mathrm{Li}$ [22] discussed the relationships of the strength, elastic modulus, Poisson's ratio, acoustic emission (AE) evolution laws, and failure characteristics with the development level of fractures in dolomite. Moreover, the researcher also revealed the influence of primary microfractures on the mechanical properties under uniaxial compression conditions. According to reciprocal energy theorem and fracture mechanics theory, $\mathrm{Xu}$ [23] discussed the changes of effective elastic modulus, shear modulus, and bulk modulus of fractured rock with the changing fracture density. Wang et al. [24] showed that correlations of the effective dynamic elastic parameters and elastic wave velocity with the fracture density in fractured rock approximate a nonlinear reciprocal function. Walsh [25] surveyed the influence of microfractures on Young's modulus through the uniaxial compression test. The research results reflect that the density of microfractures dramatically influences the mechanical properties of rock. Although some laws are drawn, whether the laws are suitable for rock with different densities of microfractures remains unclear.

Granite is selected as the surrounding rock or foundation in many major engineering projects due to its high strength and wide distribution. By taking granite from Bayu Tunnel in LhasaLinzhi Railway as the example, the rock samples without joints and with joint dip angles of $0^{\circ}$ (horizontal direction), $30^{\circ}, 45^{\circ}$, $60^{\circ}$, and $90^{\circ}$ at the coalescence rate of $50 \%$ were processed. In this way, the influence of the joint dip angle on mechanical parameters and fracture energy evolution during failure of rock samples was explored by performing the uniaxial compression test. Finally, the microscopic evolution of cracks was investigated according to numerical simulation using the PFC.

\section{Fracture and Energy Evolution Processes of Granite Samples with Different Joint Dip Angles}

2.1. The Uniaxial Compressive Strength Test on Granite with Different Joint Dip Angles. The rock samples were taken from Bayu Tunnel in Lhasa-Linzhi Railway. According to the test standard recommended by the International Society for Rock Mechanics (ISRM), the granite was prepared into standard cylindrical samples with an aspect ratio of $2: 1$ and a diameter of $50 \mathrm{~mm}$. The samples' upper and lower end faces were repeatedly ground to make their evenness within $\pm 0.05 \mathrm{~mm}$. The rock samples without joints and with the joint dip angles of $0^{\circ}$ (horizontal direction), $30^{\circ}, 45^{\circ}, 60^{\circ}$ and $90^{\circ}$ at the coalescence rate of $50 \%$ were processed and then placed for 5 weeks to be naturally air-dried. The rock samples present the average density of $2.20 \mathrm{~g} / \mathrm{cm}^{3}$, the porosity of $0.12 \%$, and the average longitudinal wave velocity of $3,370 \mathrm{~m} / \mathrm{s}$. The uniaxial compression test was carried out on standard cylindrical rock samples $(50 \mathrm{~mm} \times 100 \mathrm{~mm})$ by using the MTS815 electric hydraulic serve testing machine. The failure characteristics and stress-strain curves of the rock samples are shown in Figure 1.

As shown in Figure 1, the complete stress-strain curve of the granite can be divided into five phases: fracture compaction, elastic deformation, stable fracture propagation, accelerated fracture propagation, and post-peak strain softening.

Figure 2 shows the changes of the peak stress ratio (the ratio of the peak stress on fractured rock samples to that on intact ones) and elastic modulus ratio (the ratio of the elastic modulus of fractured rock samples to that of intact ones) with the joint dip angle.

It can be seen from Figure 2 that both the peak strength and elastic modulus of jointed samples are significantly reduced compared with the intact samples, especially for the peak strength. The peak strength declines at first and then increases with the growing dip angle of microfractures, and the strength of rock samples is the lowest at the fracture dip angle of about $45^{\circ}$. The compressive strength of the samples at the dip angle of $45^{\circ}$ takes up about $55 \%$ that of the intact samples, indicating that prefabricated fractures' presence leads to great initial damage to the samples. The peak strength significantly grows when the dip angle exceeds $45^{\circ}$. Specifically, the peak strengths at the joint dip angles of $60^{\circ}$ and $90^{\circ}$ separately account for $77.6 \%$ and $93.9 \%$ of rock without joints. The elastic modulus also drops at first and then grows with constantly increasing fracture dip angle. The elastic modulus reaches the minimum at $\alpha=45^{\circ}$, taking up about $84 \%$ of intact samples. It reveals that the samples deliver the tremendous initial damage on this condition; when the secondary fracture is perpendicular to the primary fracture (that is, $\alpha=90^{\circ}$ ), the initial damage in the samples is the least significant. The elastic modulus accounts for about $93 \%$ that of intact samples.

2.2. Analysis of the Energy Evolution Process. The failure of rock materials is attributable to energy transfer according to the theory of thermodynamics. It is supposed that rock materials of unit volume are deformed under external forces in a closed system. The energy transfer can be defined as follows according to the first law of thermodynamics:

$$
U=U^{d}+U^{e}
$$




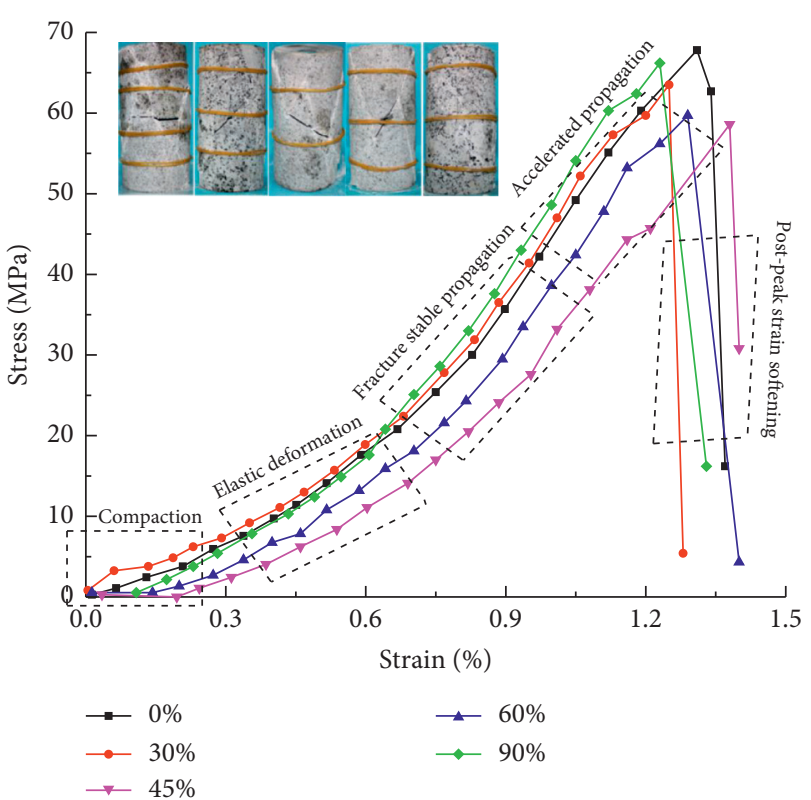

FIgURE 1: Failure characteristics and stress-strain curve.

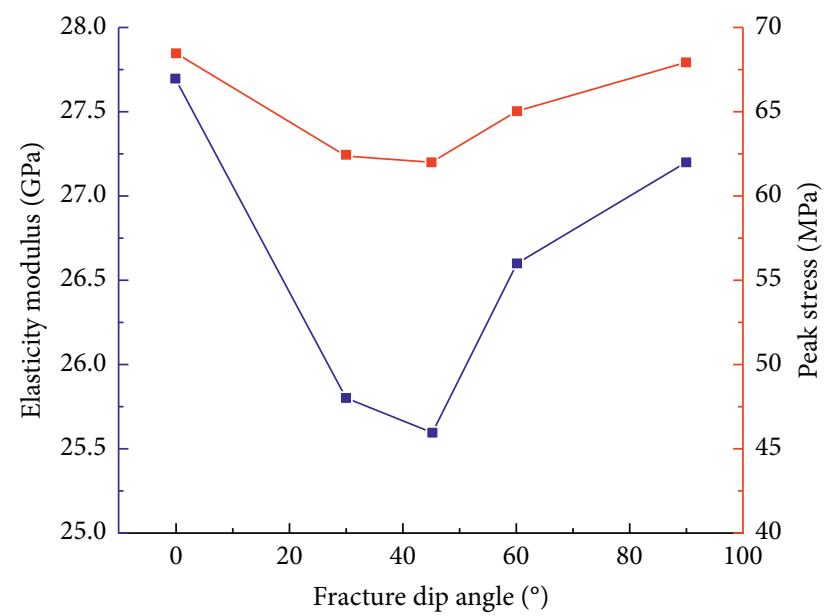

Figure 2: Peak stress ratio and elastic modulus ratio of cracked specimens.

where $U, U_{e}$, and $U_{d}$ refer to the total input strain energy, elastic strain energy, and dissipated energy, respectively.

During the conventional triaxial test, the specific formulas are displayed as follows [26]:

$$
\begin{gathered}
U=\int_{0}^{\varepsilon_{1}} \sigma_{1} \mathrm{~d} \varepsilon_{1}+2 \int_{0}^{\varepsilon_{3}} \sigma_{3} \mathrm{~d} \varepsilon_{3}+U^{0}, \\
U^{e}=\frac{1}{2 E}\left[\sigma_{1}^{2}+2 \sigma_{3}^{2}-2 \mu\left(\sigma_{1} \sigma_{3}+\sigma_{3}^{2}\right)\right],
\end{gathered}
$$

where $\sigma_{1}$ and $\sigma_{3}$ separately represent the first and third principal stresses of rock units; $\sigma_{1}$ and $\sigma_{3}$ denote the principal strains corresponding to the principal stresses on rock units, respectively; and $\mu$ and $U^{0}$ separately stand for Poisson's ratio and the elastic strain energy accumulated under the hydrostatic pressure.

$$
U^{0}=\frac{3(1-2 \mu)}{2 E} \sigma_{3}^{2}
$$

Moreover, $\sigma_{2}=\sigma_{3}=0$ exists under the uniaxial compression load, and therefore formulas (2) and (3) can be expressed as follows:

$$
\begin{aligned}
U & =\int_{0}^{\varepsilon_{1}} \sigma_{1} d \varepsilon_{1}, \\
U^{e} & =\frac{\sigma_{1}^{2}}{2 E} .
\end{aligned}
$$

Figure 3 displays the changing relationship between the elastic strain energy and the dissipated energy in rock samples under the uniaxial compression. The blank area below the stress-strain curve represents the dissipated energy $U_{d}$ caused by the internal damage and irreversible plastic deformation of rock; the triangular shadow area stands for the storable elastic strain energy $U_{e}$ in rock samples.

The energy evolution of granite samples under the uniaxial compression is shown in Figure 3. As shown in the figure, the primary fractures in the samples are gradually compressed and closed with the increasing stress in the initial compaction stage I. In this context, the total input energy nonlinearly grows with the deformation, and a majority of energy is consumed due to the microcrack closure and friction in rock. Therefore, the dissipated energy is generally slightly higher than the elastic deformation energy while a small portion of elastic strain energy is still accumulated in this phase. In the elastic deformation stage, the total energy and elastic strain energy approximately linearly grow with the increase in the strain. In this case, the compacted samples are elastic, and new cracks have not been initiated. The energy input by external forces is constantly transformed into the samples' elastic strain energy, and the dissipated energy remains the same and even drops. The dissipated energy in intact rock samples is about $10 \mathrm{~kJ} / \mathrm{m}^{3}$, generally higher than that in rock samples with fractures.

Moreover, the change of the dissipated energy is closely related to the fracture dip angle. At the dip angles of $0^{\circ}$ and $30^{\circ}$, the dissipated energies in the elastic deformation stage are about 3 and $7 \mathrm{~kJ} / \mathrm{m}^{3}$, respectively. On this condition, the energy is insignificantly dissipated. At the dip angles of $45^{\circ}$, $60^{\circ}$, and $90^{\circ}$, the samples are subjected to brittle failure even after minor deformation. Therefore, the elastic deformation stage lasts for a short time, and the dissipated energy drops. It indicates that the cracks or fractures in rock samples are further compacted, and the proportion of the elastic strain energy further increases. In the plastic weakening stage, the applied load gradually approximates the peak stress. In this case, the samples are subjected to plastic deformation, and microfractures constantly develop to form regional damage and friction between cracks gradually. Part of the externally input energy is dissipated due to the change of the internal structure, and thus the dissipated energy starts to increase. The intact samples without prefabricated fractures exhibit strong brittleness, and they are rapidly damaged after reaching the peak strength when new cracks initiate. 

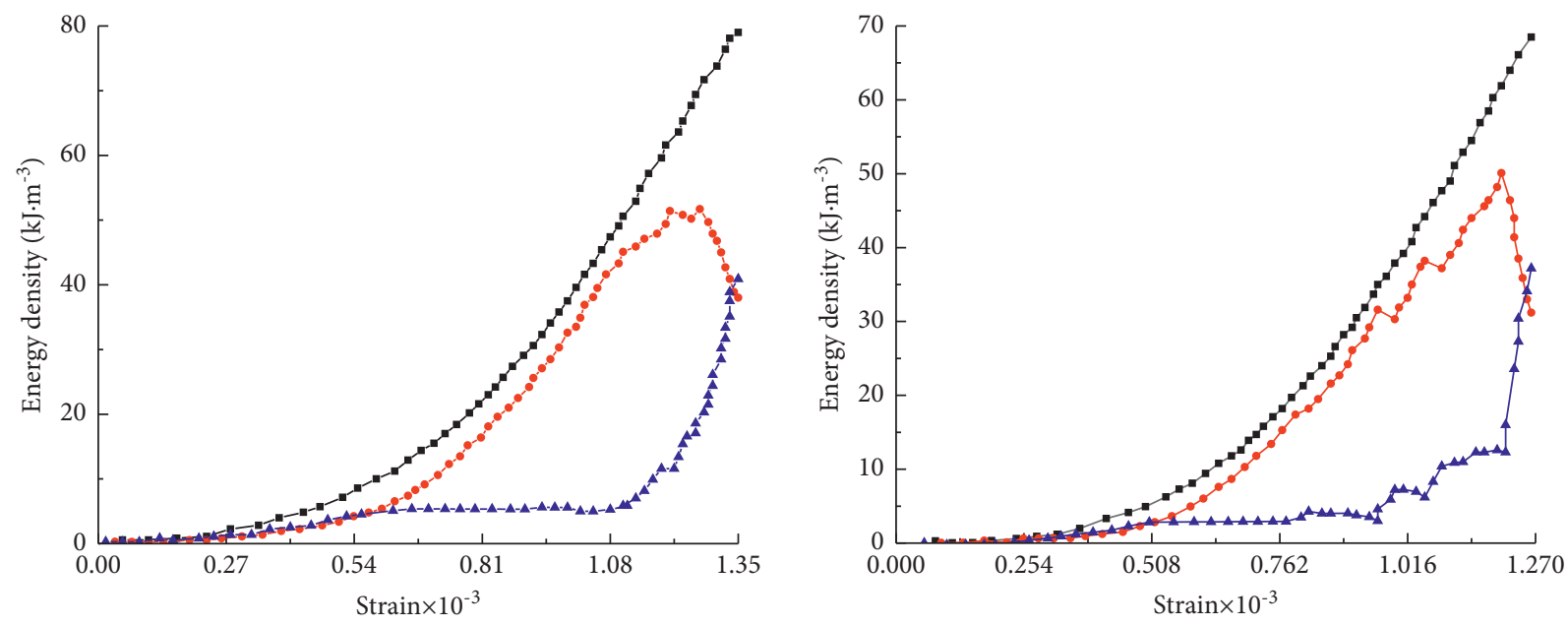

$$
\begin{aligned}
& \rightarrow U \\
& \rightarrow U^{\mathrm{e}} \\
& \because U^{\mathrm{d}}
\end{aligned}
$$$$
\rightarrow U
$$$$
\rightarrow U^{e}
$$$$
\rightarrow U^{\mathrm{d}}
$$

(a)
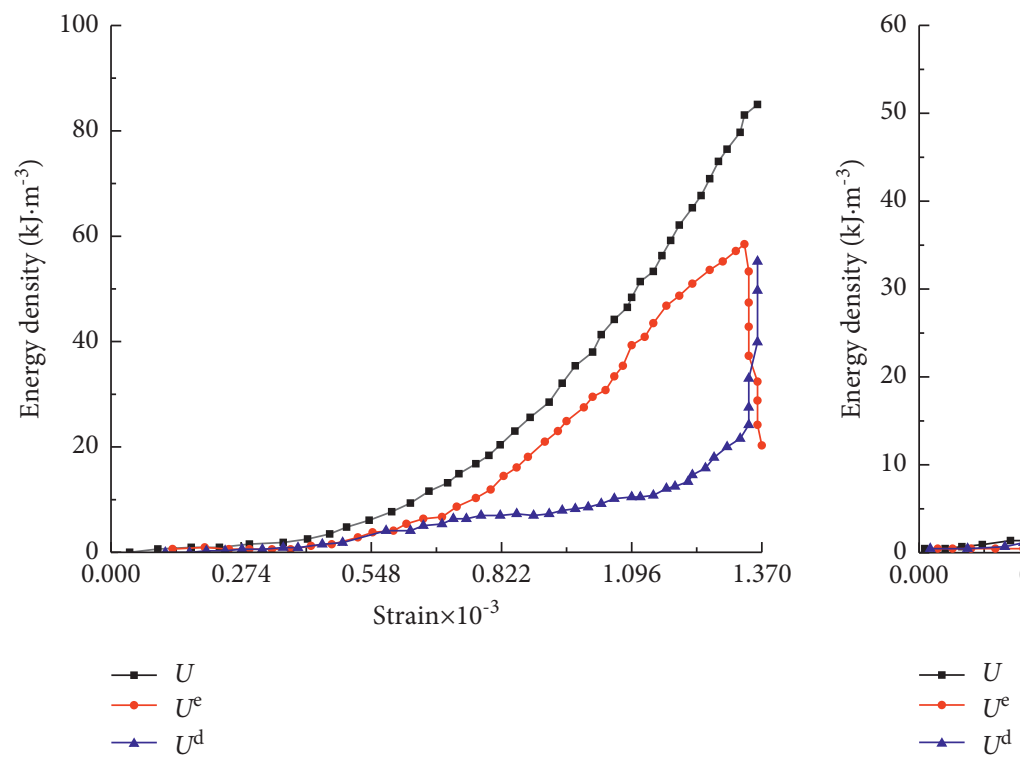

(b)

(c)

(d)

Figure 3: Continued. 


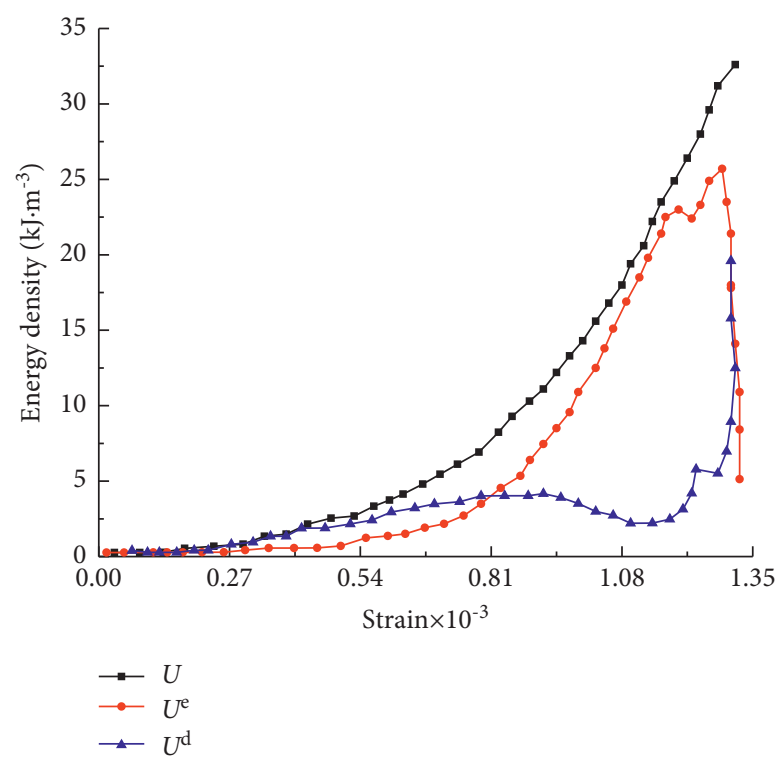

(e)

Figure 3: Energy evolution of intact specimens: (a) $\alpha=0^{\circ}$; (b) $\alpha=30^{\circ}$; (c) $\alpha=45^{\circ}$; (d) $\alpha=60^{\circ}$; (e) $\alpha=90^{\circ}$.

Therefore, the plastic weakening stage almost hardly exists for the intact samples without prefabricated fractures. For the samples with prefabricated fractures, new cracks firstly initiate and then the prefabricated fractures further propagate and coalesce. This process causes the significant growth of dissipated energy. At the dip angles of $0^{\circ}, 30^{\circ}, 60^{\circ}$, and $90^{\circ}$, the constantly accumulated elastic strain is suddenly released with the growing deformation. The curve of elastic strain energy drops in a step manner while the dissipated energy curve suddenly rises in a step manner. At the dip angle of $45^{\circ}$, the dissipated energy gradually increases. At the same time, it does not grow in a step manner, which implies that the fractures with a dip angle of $45^{\circ}$ do not trigger the initiation and propagation of cracks in advance. In the brittle failure stage IV, the failure of the rock samples starts after reaching the peak strength. The elastic strain energy accumulated in the rock samples is rapidly released on this condition while the plastic deformation dramatically increases. As the microfractures in rock samples constantly develop, the cracks quickly propagate and coalesce, and the rock samples start to lose the bearing capacity, showing significant brittle characteristics. In the brittle failure stage, the dissipated energy sharply grows while the elastic strain energy rapidly reduces with the growth of the strain. The curves of the dissipated energy and elastic strain energy are intersected.

\section{Establishment of the Discrete Element Model}

3.1. Analysis of the Fracture Process. The biaxial compression test was carried out on rock materials using the PFC2D. The simulation model shows the dimensions of $50 \mathrm{~mm} \times 100 \mathrm{~mm}$, and the loading equipment was simulated with walls. The mesoscopic parameters of the model were obtained (Table 1) through inversion analysis based on the parameter sensitivity analysis. As shown in Figure 4, the simulated curve favors the test curve, which provides a basis for numerical analysis research during rock failure. The rock models with a single joint on different working conditions were designed by changing the joint dip angle $\left(\alpha=0^{\circ}, 30^{\circ}\right.$, $45^{\circ}, 60^{\circ}$, and $90^{\circ}$ ), in which the joint with the length of $25 \mathrm{~mm}$ is noncoalescent.

It can be seen from Figure 5 that the number of cracks (total cracks, tensile cracks, and shear cracks) generally increases in an $S$ shape at any joint dip angle during the uniaxial compression loading test. The cracks experience four processes, i.e., without cracks, slow initiation, rapid growth, and gradually decreasing growth rate, showing a significant regularity. On this basis, the crack propagation process of the samples is divided into the elastic stage without cracks, crack initiation stage, rapid crack propagation stage, and slow crack development stage. The fracture mode shows different proportions at different dip angles. Figure 5 displays the curve of the cumulative number of cracks in the samples, and Figure 5 shows the spatial distribution of cracks within four stages.

As shown in Figure 5, in elastic stage without cracks, the samples are subjected to elastic deformation, and no cracks appear therein. The stress-strain curve approximately linearly develops.

In crack initiation stage, cracks initiate and propagate, and the crack growth curve is nonlinearly concaved. In this case, the crack initiation strength is $52.1 \mathrm{MPa}$, which takes up $64.88 \%$ in the compressive strength of intact samples; the cracks are distributed stochastically, and the number of shear cracks approximately equals that of tensile cracks.

In rapid crack propagation stage, the number of cracks linearly rapidly grows, and the tensile cracks more quickly increase than shear cracks when approaching the peak stress. The interaction and interference among cracks become more 
TABLE 1: Model parameters of rock.

\begin{tabular}{lccccccc}
\hline Types of materials & Particle size $(\mathrm{m})$ & Density $\left(\mathrm{kg} / \mathrm{m}^{3}\right)$ & Emod $(\mathrm{GPa})$ & Krat & Pb_ten $(\mathrm{MPa})$ & $\mathrm{Pb} \_\mathrm{coh}(\mathrm{MPa})$ & $\mathrm{Pb} \_f a\left({ }^{\circ}\right)$ \\
\hline Granite & $0.3 e^{-3}-0.5 e^{3}$ & 2950 & 48.57 & 1.7 & 24.6 & 12.5 \\
\hline
\end{tabular}

Note. Krat: stiffness ratio; $\mathrm{Pb} \_$ten: tensile strength; $\mathrm{Pb} \_$coh: cohesion; $\mathrm{Pb} \_$fa: friction angle.

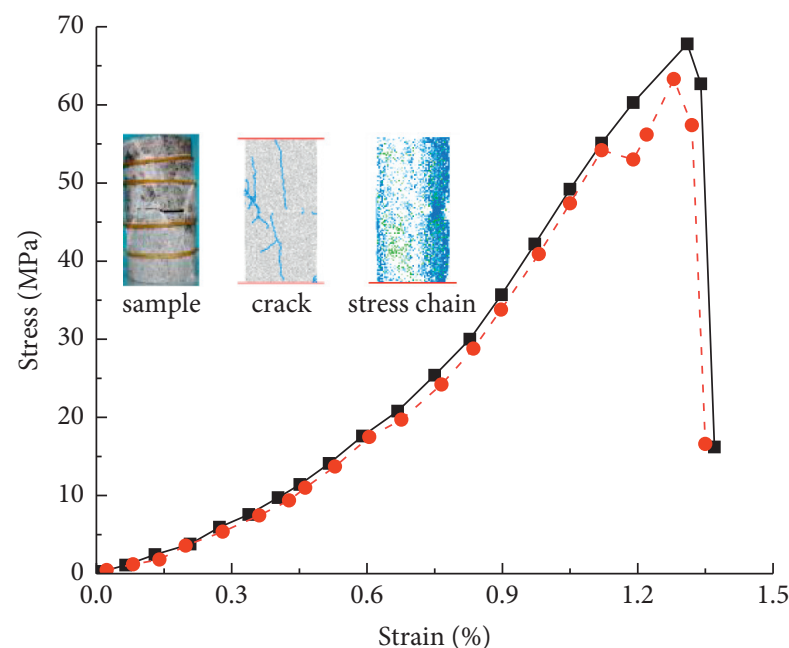

$\rightarrow-$ Testing Curve

- - Simulated curves

(a)

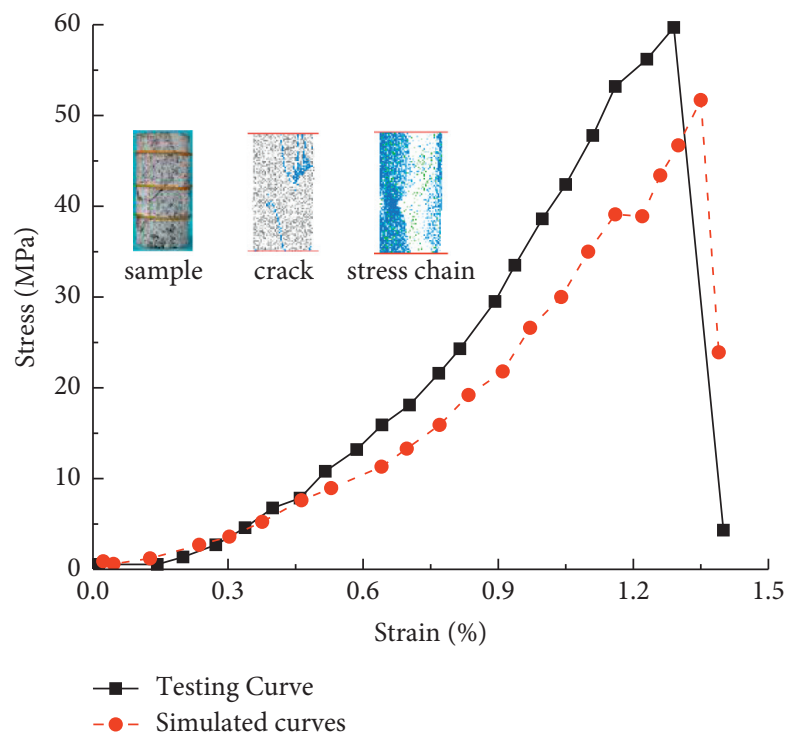

(c)

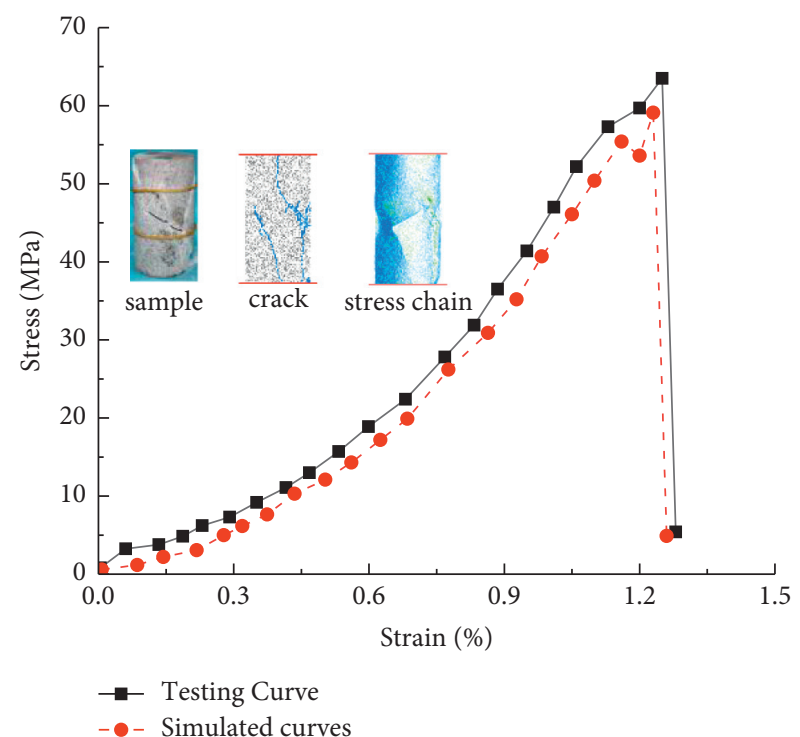

(b)

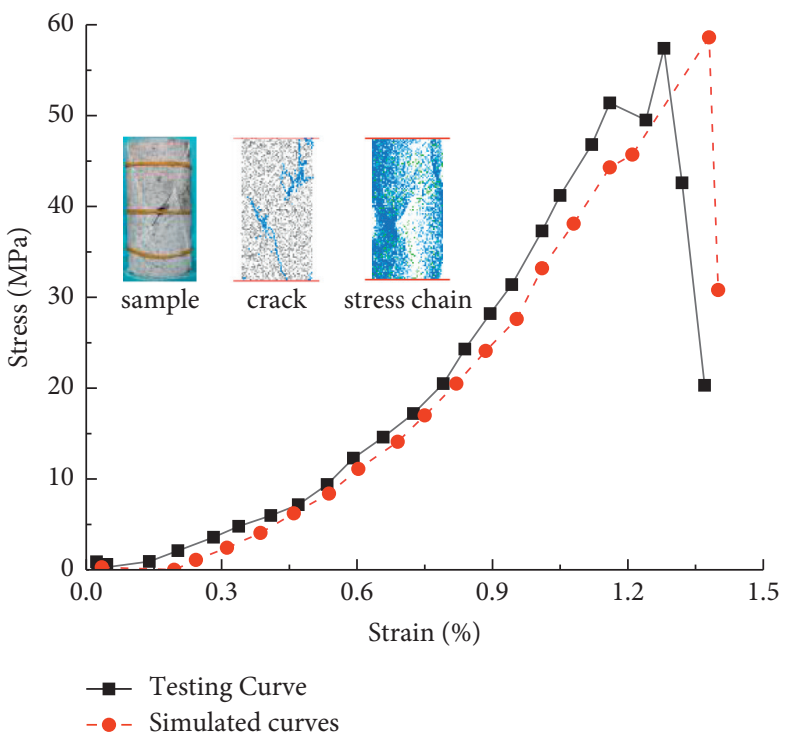

(d)

Figure 4: Continued. 


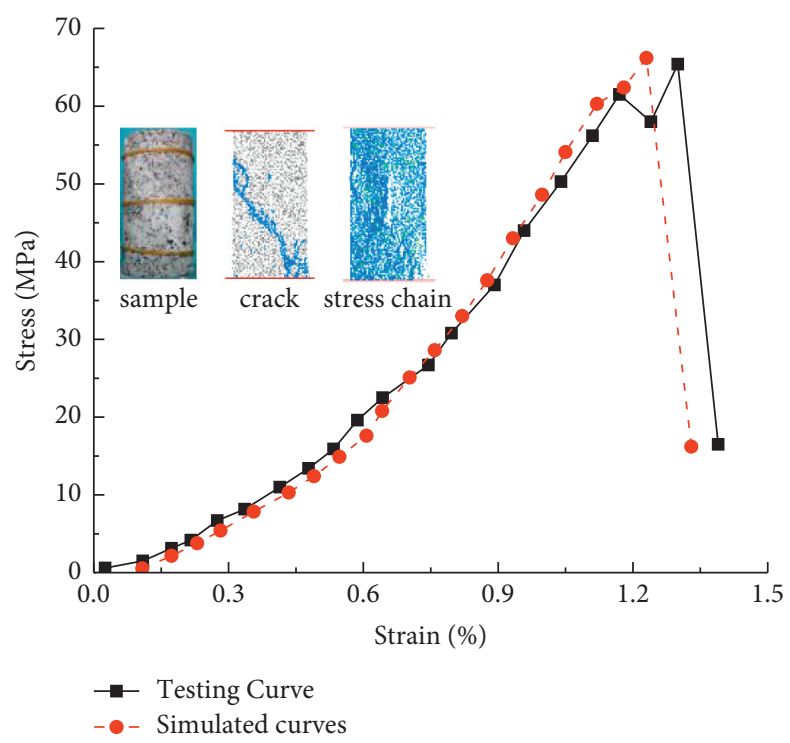

(e)

Figure 4: Failure characteristics of joint samples under uniaxial compression: (a) $\alpha=0^{\circ}$, (b) $\alpha=30^{\circ}$, (c) $\alpha=45^{\circ}$, (d) $\alpha=60^{\circ}$, and (e) $\alpha=90^{\circ}$.
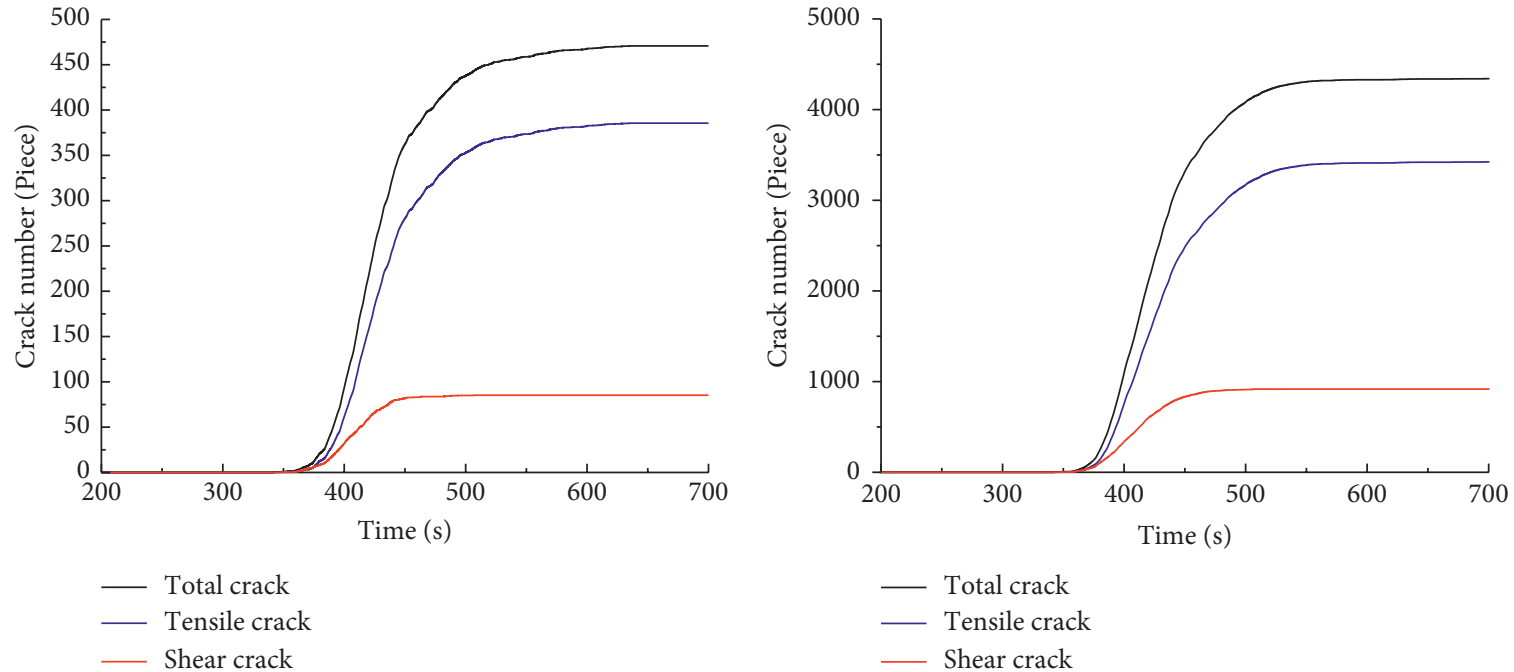

(a)
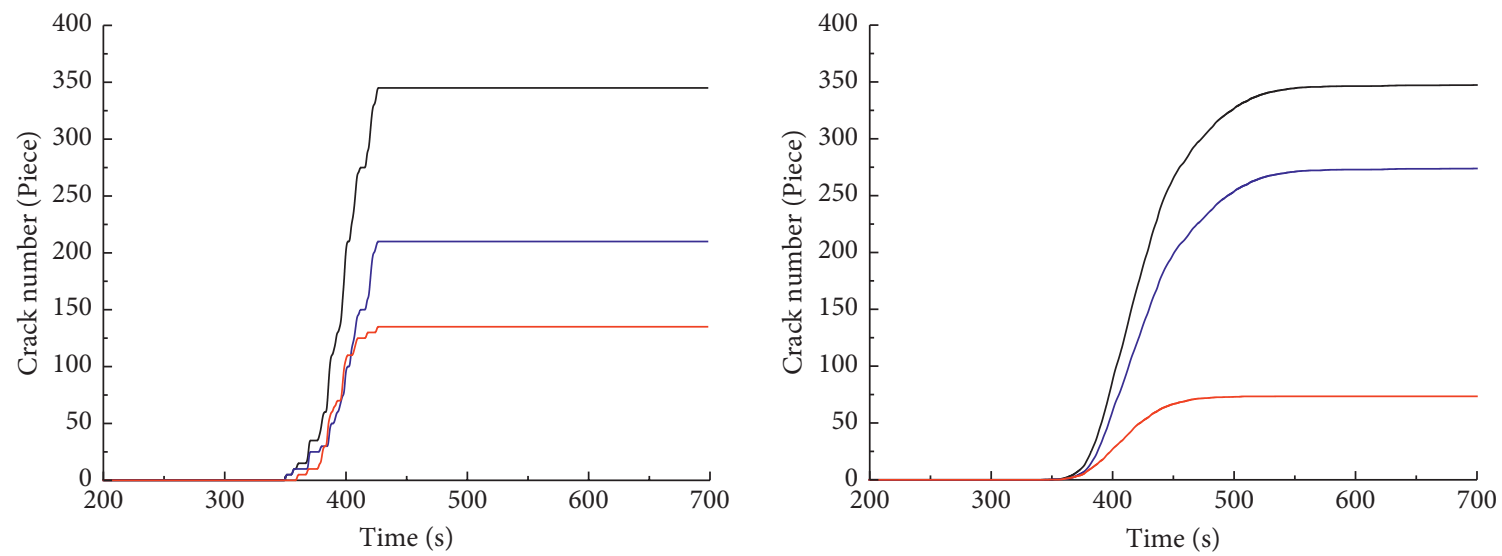

Total crack

Tensile crack

Total crack

Tensile crack

_ Shear crack

(c)

Figure 5: Continued. 


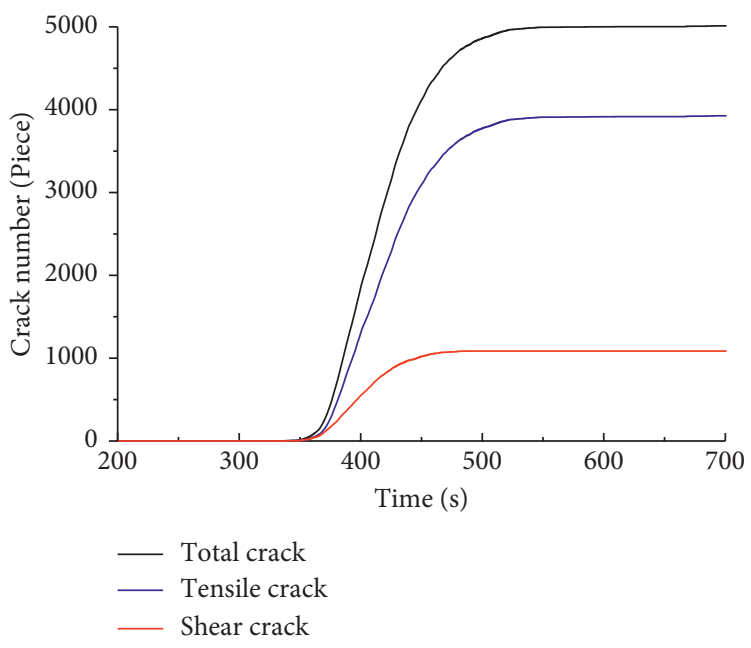

(e)

Figure 5: Crack evolution characteristics: (a) $\alpha=0^{\circ}$; (b) $\alpha=30^{\circ}$; (c) $\alpha=45^{\circ}$; (d) $\alpha=60^{\circ}$; (e) $\alpha=90^{\circ}$.

apparent, and cracks constantly develop, agglomerate, and nucleate owing to the increase in density of cracks drastically. On this condition, the growth of the density of mesoscopic cracks improves the nonlinear characteristics of the mechanical properties of rock.

In slow crack development stage, the number of cracks slowly rises, and 3,837 cracks are finally generated, in which the tensile and shear cracks separately account for about $75.3 \%$ and $24.7 \%$. The samples are subjected to tensile failure under the leading role of tensile fractures, thus forming macroscopic cracks developing nearly along the axial direction.

3.2. Law of Characteristic Failure Strength of the Model. As shown in Figure 6, the microfractures in rock start to initiate and propagate when the loading stress is higher than the crack initiation stress of rock. If the loading stress is higher than the damage stress of rock, numerous internal microfractures are connected and then coalesced. The cracks further propagate and coalesce without the need to increase the external force. In this context, the number of cracks rapidly grows and the curve of the volumetric strain is bent and rock is subjected to volume expansion. Therefore, the corresponding axial stress at the point where cracks initiate is taken as the crack initiation stress. The damage stress can be determined by taking the related axial stress at the point where cracks rapidly increase or the corresponding axial stress at the point where the curve of the volumetric strain of rock is bent. During the uniaxial compression simulation test on rock using PFC, microcracks are monitored, and the volumetric strain of rock is monitored by setting the measuring circles. Therefore, the corresponding axial stress at the point where microcracks initiate is taken as the crack initiation stress of jointed granite during the simulation; the damage stress can be determined according to the number of microcracks or the volumetric strain.

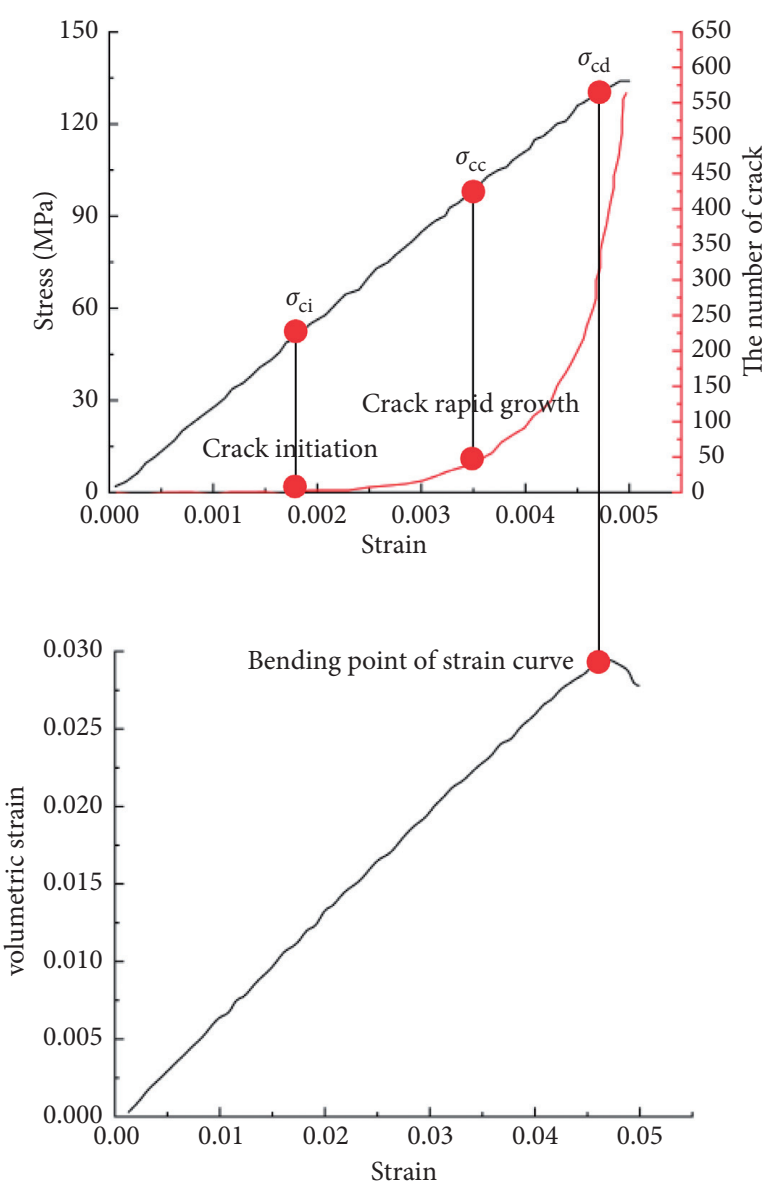

FIGURE 6: Cracks and volumetric strain in intact granite.

Figure 7 shows the strength eigenvalue under different fracture dip angles. The crack initiation stress gradually declines at $0^{\circ}<\alpha \leq 45^{\circ}$. The crack initiation stress is the lowest at $\alpha=45^{\circ}$ while it slowly rises at $45^{\circ}=\alpha<90^{\circ}$. Additionally, cracks are hard to initiate, and there is relatively high crack 


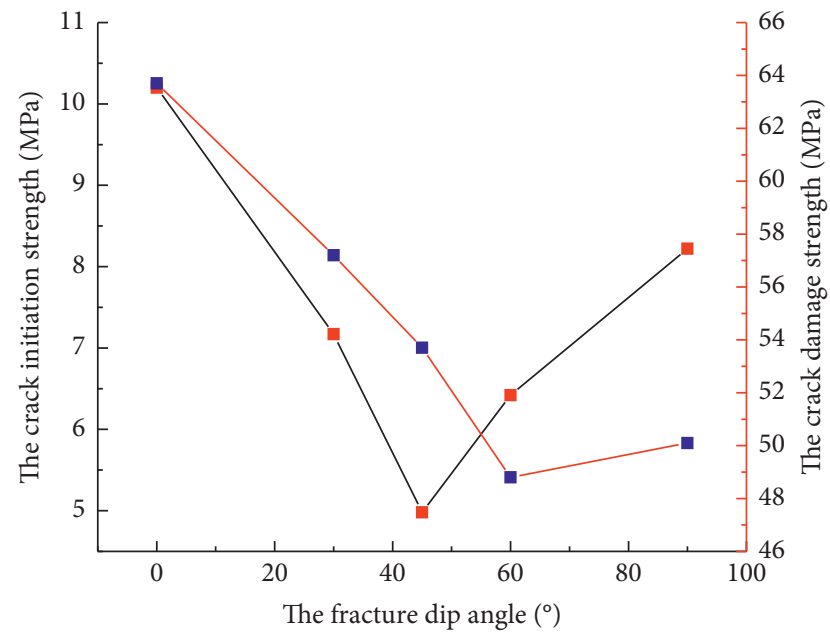

Figure 7: The strength eigenvalue under different fracture dip angles.

initiation stress at $\alpha=0^{\circ}$; that is, the joint direction is parallel to the loading direction. It is easy for cracks to initiate, and the crack initiation stress is relatively low at $\alpha=90^{\circ}$; that is, the joint direction is perpendicular to the loading direction. It can be seen through the above analysis that the crack initiation stress gradually reduces at first and then gradually grows with the increasing $\alpha$. The crack initiation stress declines at $\alpha=90^{\circ}$, and it reaches the minimum at $\alpha=45^{\circ}$. It can be seen from the figure that the damage stress declines at first and then gradually increases with the growing $\alpha$. The damage stress gradually reduces with the growth of $\alpha$ within the range of $0^{\circ} \sim 30^{\circ}$. There is the lowest damage stress at $\alpha=30^{\circ}$. Then, the damage stress gradually grows with the increase in $\alpha$ within the range of $30^{\circ} \sim 90^{\circ}$.

\section{Conclusions}

The uniaxial compression tests were conducted on granite samples with different joint dip angles to explore the effect of the nonconsecutive joint on mechanical characteristics. The main conclusions are as follows:

(1) Both the peak strength and elastic modulus of jointed samples drop obviously compared with intact samples, especially for the peak strength. The compressive strength and elastic modulus are the minima in the samples at the dip angle of $45^{\circ}$. The uniaxial strength accounts for about 55\% of the compressive strength, while the elastic modulus takes up about $84 \%$ of intact samples.

(2) A comparison is made on the crack initiation stresses and damage stresses obtained through uniaxial compression simulation using PFC and laboratory tests on intact granites. Furthermore, the method of acquiring the crack initiation stress and damage stress on jointed granite by monitoring microfractures is determined. The determined crack initiation stress and the damage stress coincided with the results attained through the laboratory test.
(3) The crack initiation stress gradually reduces at the joint dip angle of $0^{\circ} \sim 45^{\circ}$, and it reaches the minimum at $\alpha=45^{\circ}$; moreover, the crack initiation stress gradually increases at the joint dip angle of $45^{\circ} \sim 90^{\circ}$. The damage stress declines at first and then grows with the increasing joint dip angle. The damage stress gradually reduces with the rising joint dip angle within the range of $0^{\circ} \sim 30^{\circ}$, and it reaches the lowest at $\alpha=30^{\circ}$; the damage stress gradually rises with the growing joint dip angle within the range of $30^{\circ} \sim 90^{\circ}$.

\section{Data Availability}

The data used to support the findings of this study are available from the corresponding author upon request.

\section{Conflicts of Interest}

The authors declare that there are no conflicts of interest.

\section{Acknowledgments}

The authors sincerely thank the https://dx.doi.org/10.13039/ 501100001809National Natural Science Foundation of China (42061011; 41977236; 41672278) and https:// dx.doi.org/10.13039/501100004479Natural Science Foundation of Jiangxi Province (20192ACBL20002).

\section{References}

[1] Q. Jiang, X. Feng, L. Song, Y. Gong, H. Zheng, and J. Cui, "Modeling rock specimens through 3D printing: tentative experiments and prospects," Acta Mechanica Sinica, vol. 32, no. 1, pp. 101-111, 2016.

[2] L. Song, Q. Jiang, Y.-E. Shi et al., "Feasibility investigation of 3D printing technology for geotechnical physical models: study of tunnels," Rock Mechanics and Rock Engineering, vol. 51, no. 8, pp. 2617-2637, 2018.

[3] P. Shan and X. Lai, "Mesoscopic structure PFC 2D model of soil rock mixture based on digital image," Journal of Visual Communication and Image Representation, vol. 58, no. 1, pp. 407-415, 2019.

[4] Z. G. Shi, Z. H. Shui, Q. Li, and H. N. Geng, "Combined effect of metakaolin and sea water on performance and microstructures of concrete," Construction and Building Materials, vol. 74, no. 74, pp. 57-64, 2014.

[5] G. Wang, Y. Luo, X. Li, T. Liu, M. Xu, and D. Qu, "Study on dynamic mechanical properties and meso-deterioration mechanism of sandstone under cyclic impact load," Arabian Journal for Science and Engineering, vol. 45, no. 5, pp. 3863-3875, 2020.

[6] Y. H. Li, L. B. Song, Q. Jiang, C. Yang, C. Liu, and B. Yang, "Shearing performance of natural matched joint with different wall strengths under direct shearing test," Geotechnical Testing Journal, vol. 41, no. 2, pp. 371-389, 2018.

[7] T. T. Liu, J. C. Li, H. B. Li, X. Li, Y. Zheng, and H. Liu, "Experimental study of S-wave propagation through a filled rock join," Rock Mechanics and Rock Engineering, vol. 50, no. 10, pp. 1-13, 2017.

[8] Y. Luo, G. Wang, X. P. Li et al., "Analysis of energy dissipation and crack evolution law of sandstone under impact load," 
International Journal of Rock Mechanics and Mining Sciences, vol. 132, Article ID 104359, 2020.

[9] X. Zhang, Y. Jiang, G. Wang et al., "Mechanism of shear deformation, failure and energy dissipation of artificial rock joint in terms of physical and numerical consideration," Geosciences Journal, vol. 23, no. 3, pp. 519-529, 2019.

[10] S. Q. Yang, D. S. Yang, H. W. Jing, Y. H. Li, and S. Y. Wang, "An experimental study of the fracture coalescence behaviour of brittle sandstone specimens containing three fissures," Rock Mechanics and Rock Engineering, vol. 45, no. 4, pp. 563-582, 2012.

[11] R. M. Holt, J. Kjlaas, I. Larsen, and L. Li, "Comparison between controlled laboratory experiments and discrete particle simulations of the mechanical behaviour of rock," International Journal of Rock Mechanics and Mining Sciences, vol. 42, no. 7, pp. 985-995, 2005.

[12] C. Gehle and H. K. Kutter, "Breakage and shear behaviour of intermittent rock joints," International Journal of Rock Mechanics and Mining Sciences, vol. 40, no. 5, pp. 687-700, 2003.

[13] L. Fan, H. M. Zhou, and Y. H. Zhang, "Influence of microcracks on strength parameters of engineering rock mass," Chinese Journal Of Rock Mechanics And Engineering, vol. 30, no. 1, pp. 2703-2709, 2011.

[14] L. Fan, L. Jiang, and Q. F. Hu, "Influence of microcracks on deformation parameters of engineering rock mass," Journal of Yangtze River Scientific Research Institute, vol. 30, no. 2, pp. 27-103, 2013.

[15] Z. Y. Zhao, H. Q. Zhang, C. A. Tang, and S. Y. Wang, "Numerical study on breakage and shear behavior of intermittent rock joints," in Proceedings of the Geoshanghai International Conference, pp. 248-253, China, Shanghai, May 2014.

[16] D. E. Moore and D. A. Lockner, "The role of microcracking in shear-fracture propagation in granite," Journal of Structural Geology, vol. 17, no. 1, pp. 95-114, 1995.

[17] S. Q. Kou and O. Alm, "Microcracks and the tensile strength of granite," Acta Mechanica Sinica, vol. 19, no. 4, pp. 76-83, 1987.

[18] W. Q. Feng, "Research of fissure effect on rock mechenical properties," Design of Hydroelectric Power Station, vol. 3, pp. 28-35, 1991.

[19] P. Wang, K. Z. Huang, and J. T. Zhou, "Relationship between the microcrack density and mechanical properties of marble," Journal of Engineering Geology, vol. 4, no. 2, pp. 19-23, 1996.

[20] R. H. C. Wong, K. T. Chau, and P. Wang, "Microcracking and grain size effect in Yuen Long marbles," International Journal of Rock Mechanics and Mining Science \& Geomechanics Abstracts, vol. 33, no. 5, pp. 479-485, 1996.

[21] C. Z. Pu, P. Cao, Y. L. Zhao, X. Y. Zhang, Y. L. Yi, and Y. K. Liu, "Numerical analysis and strength experiment of rock-like materials with multi-fissures under uniaxial compression," Rock and Soil Mechanics, vol. 31, no. 11, pp. 3661-3666, 2010.

[22] X. X. Li, Influence of Primary Microcracks on Mechanical Properties of Dolomite under Uniaxial Compression, Kunming University of Science and Technology, Kunming, China, 2015.

[23] W. Y. Xu, "A simple method to estimate the effective elastic moduli of cracked rock," Journal of Hehai University, vol. 31, no. 4, pp. 399-402, 2003.

[24] H. T. Wang, X. H. Li, C. H. Yang, H. G. Zhong, J. J. Qing, and X. Z. Xin, "Influence of cracks on the propagation properties of elastic waves in quasi-isotropic cracked rock masses," Rock And Soil Mechanics, vol. 26, no. 6, pp. 873-876, 2005.
[25] J. B. Walsh, "The effect of cracks on the uniaxial elastic compression of rocks," Journal Of Geophysical Research, vol. 70, no. 2, pp. 399-411, 1965.

[26] H. P. Xie, R. D. Peng, Y. Ju, and H. Zhou, "On energy analysis of rock failure," Chinese Journal of Rock Mechanics and Engineering, vol. 24, no. 15, pp. 2603-2608, 2005. 